\title{
MP2 calculations of the effect of the $\pi$-conjugation on the electronic and nonlinear optical properties of para-nitroaniline (pNA) derivatives
}

\author{
Nuha Wazzan ${ }^{1}$ \\ ${ }^{1}$ King Abdulaziz University
}

May 11, 2020

\begin{abstract}
long-range charge transfer organic compounds are remarkable for having very large hyperpolarizabilities and thus improved nonlinear optical (NLO) properties. p-nitroaniline (pNA) is known as a prototypical NLO organic material. The question answered in this work is the NLO properties of pNA will be improved by introducing an extended $\pi$-conjugation chain between the phenyl ring and the two NH2/NO2 terminal? By means of sophisticated ab initio/MP2 calculations, new derivatives of pNA with an extended $\pi$-conjugation have been designed by introducing $-(\mathrm{CH}=\mathrm{CH}) \mathrm{nNH} 2$ or $-(\mathrm{CH}=\mathrm{CH}) \mathrm{nNO} 2(\mathrm{n}=1-5)$ chain into pNA. The results indicate that introducing such chains results in smaller energy gaps and transition energies, which lead to a significant improvement in the hyperpolarizability $\left(\beta_{-} 0\right)$. The novel pNA derivatives exhibit larger $\beta \_0$ amplitudes up to $4.67 \times 104 \mathrm{au}$, which is 27 -fold greater than that of pNA. Moreover, with increasing the $\beta \_0$ amplitude, the $-(\mathrm{CH}=\mathrm{CH}) \mathrm{nNO} 2$ chain beats the $-(\mathrm{CH}=\mathrm{CH}) \mathrm{nNH} 2$ chain. It is hoped that this study can provide a help for designing higher performance NLO materials based on pNA.
\end{abstract}

\section{Hosted file}

PNA_NLO_MANUSCRIPT_IJQC.docx available at https://authorea.com/users/320330/articles/450199mp2-calculations-of-the-effect-of-the-\%CF\%80-conjugation-on-the-electronic-andnonlinear-optical-properties-of-para-nitroaniline-pna-derivatives 